Article

\title{
A Novel Schiff Base of 3-acetyl-4-hydroxy-6-methyl-(2H)pyran- 2-one and 2,2'-(ethylenedioxy)diethylamine as Potential Corrosion Inhibitor for Mild Steel in Acidic Medium
}

\author{
Jonnie N. Asegbeloyin 1, Paul M. Ejikeme 1, Lukman O. Olasunkanmi ${ }^{2,3}$, \\ Abolanle S. Adekunle ${ }^{2,3}$ and Eno E. Ebenso ${ }^{2, *}$
}

1 Department of Pure and Industrial Chemistry, University of Nigeria, Nsukka 40001, Enugu State, Nigeria; E-Mails: niyi.asegbeloyin@unn.edu.ng (J.N.A.); paul.ejikeme@unn.edu.ng (P.M.E.)

2 Material Science Innovation and Modelling (MaSIM) Research Focus Area, Faculty of Agriculture, Science and Technology, North-West University (Mafikeng Campus) Private Bag X2046, Mmabatho 2735, South Africa; E-Mails: waleolasunkanmi@gmail.com (L.O.O.); sadekpreto@gmail.com (A.S.A.)

3 Department of Chemistry, Faculty of Science, Obafemi Awolowo University, Ile-Ife 220005, Nigeria

* Author to whom correspondence should be addressed; E-Mail: Eno.Ebenso@nwu.ac.za; Tel.: +27-18-389-2113 or +27-18-389-2050 or +27-18-389-2051; Fax: +27-18-389-2052.

Academic Editor: Jorge de Brito

Received: 18 March 2015 / Accepted: 12 May 2015 / Published: 26 May 2015

\begin{abstract}
The corrosion inhibition activity of a newly synthesized Schiff base (SB) from 3-acetyl-4-hydroxy-6-methyl-(2H)-pyran-2-one and 2,2'-(ethylenedioxy)diethylamine was investigated on the corrosion of mild steel in $1 \mathrm{M} \mathrm{HCl}$ solution using potentiodynamic polarization and electrochemical impedance spectroscopic techniques. Ultraviolet-visible (UV-vis) and Raman spectroscopic techniques were used to study the chemical interactions between SB and mild steel surface. SB was found to be a relatively good inhibitor of mild steel corrosion in $1 \mathrm{M} \mathrm{HCl}$. The inhibition efficiency increases with increase in concentration of SB. The inhibition activity of SB was ascribed to its adsorption onto mild steel surface, through physisorption and chemisorption, and described by the Langmuir adsorption model. Quantum chemical calculations indicated the presence of atomic sites with potential nucleophilic and electrophilic characteristics with which SB can establish electronic interactions with the charged mild steel surface.
\end{abstract}


Keywords: Schiff base; electrochemical techniques; mild steel; adsorption; quantum chemical calculations

\section{Introduction}

Mild steel is used in many industrial and structural applications due to its good mechanical strength and relatively low cost $[1,2]$. Acidic solutions commonly used in many industrial activities, including the steelmaking finishing process, constitute unfriendly corrosive media for mild steel [3]. The use of organic corrosion inhibitors has been identified as one of the most economical ways of reducing corrosion rate and protecting steel-made industrial facilities against corrosion $[3,4]$. The ability of Schiff base ligands to form stable complexes closely packed in the coordination sphere of metal ion introduces another class of compounds for corrosion inhibition [5]. Schiff bases are adsorbed on metal surfaces due to the presence of $>\mathrm{C}=\mathrm{N}-$ groups [6]. This adsorption behavior leads to spontaneous formation of a monolayer covering the metal surface, consequently acting as effective corrosion inhibitor.

3-acetyl-4-hydroxy-6-methyl-(2H) pyran-2-one, commonly referred to as dehydroacetic acid, and its derivatives have been of research interest because of their interesting coordination chemistry, pharmaceutical importance and biological activities [7-11]. DNA binding and antibacterial screening of dehydroacetic acid complexes of $\mathrm{Ru}(\mathrm{II})$ and $\mathrm{Ru}(\mathrm{III})$ containing $\mathrm{PPh}_{3} / \mathrm{AsPh}_{3}$ have been recently reported by Chitrapriya et al. [12]. Dehydroacetic acid is well known for its fungicidal [13], herbicidal and antimicrobial activities [10]. It is also widely used in food technology, as a vitamin C stabilizer and as a preservative in food products like fish sausages [14]. Therefore, dehydroacetic acid and possibly its Schiff bases, are non-toxic and eco-friendly. The presence of $\mathrm{O}$ and $\mathrm{N}$ heteroatoms as well as $>\mathrm{C}=\mathrm{N}-$ and $>\mathrm{C}=\mathrm{O}$ functional groups in dehydroacetic acid/2,2'-(ethylenedioxy)diethylamine Schiff base may facilitate electronic interactions with a mild steel surface, leading to adsorption on the steel surface and consequently, inhibition of steel corrosion.

The present work is in furtherance of the continual search for eco-friendly, easy to synthesize and effective corrosion inhibitors. In this work, a novel Schiff base (SB) was synthesized based on condensation of 3-acetyl-4-hydroxy-6-methyl-(2H)pyran-2-one and 2,2'-(ethylenedioxy)diethylamine and investigated for its corrosion inhibition activities using electrochemical methods, spectroscopic techniques and quantum chemical calculations.

\section{Results and Discussion}

\subsection{Synthesis of $S B$}

The results of IR, NMR and elemental analyses confirmed successful synthesis of SB with the chemical structure (SB) shown under the experimental Section 3.3. The percentage yield and melting point of the whitish compound $\left(\mathrm{C}_{22} \mathrm{H}_{28} \mathrm{~N}_{2} \mathrm{O}_{8}\right)$ synthesized were $85 \%$ and $155{ }^{\circ} \mathrm{C}$, respectively. The infrared, proton and carbon-13 NMR spectroscopic results of the product are given in Table 1. Detail assignments of these spectroscopic data have been described somewhere else [15]. 
Table 1. IR, ${ }^{1} \mathrm{HNMR},{ }^{13} \mathrm{CNMR}$ spectroscopy data and elemental analysis of SB.

\begin{tabular}{ccc}
\hline $\mathrm{IR}\left(\mathrm{KBr} \mathrm{cm}^{-1}\right)$ & $1665(\mathrm{C}=\mathrm{N}), 3454(\mathrm{OH}), 1703(\mathrm{C}=\mathrm{O}), 1254(\mathrm{C}-\mathrm{O}), 1358(\mathrm{C}-\mathrm{N})$ \\
\hline \multirow{2}{*}{${ }^{1} \mathrm{H} \mathrm{NMR}\left(\mathrm{CDCl}_{3}, \delta, \mathrm{ppm}\right)$} & $2.11\left(\mathrm{~s}, 3 \mathrm{H},-\mathrm{C}=\mathrm{C}-\mathrm{CH}_{3}\right) ; 2.50\left(\mathrm{~s}, 3 \mathrm{H}, \mathrm{N}=\mathrm{C}-\mathrm{CH}_{3}\right) ; 5.62\left(\mathrm{~s}, 1 \mathrm{H}, \mathrm{CH}_{3}=\mathrm{C}-\mathrm{H}\right) ;$ \\
& $3.27 \delta(\mathrm{s}, 4 \mathrm{H}) ; 3.70 \delta(\mathrm{m}, 6 \mathrm{H}) ; 13.80 \delta(\mathrm{s}, 1 \mathrm{H}$, enolic OH$)$ \\
\hline \multirow{2}{*}{${ }^{13} \mathrm{C} \mathrm{NMR}\left(\mathrm{CDCl}_{3}, \delta, \mathrm{ppm}\right)$} & $18.27,19.58\left(-\mathrm{CH}_{3}\right), 183.66(\mathrm{O}-\mathrm{C}=\mathrm{O}) ; 176.03(\underline{\mathrm{C}}-\mathrm{OH}) ; 162.47\left(\mathrm{H}_{3} \mathrm{C}-\underline{\mathrm{C}}-\mathrm{O}\right) ;$ \\
& $107.49(\mathrm{C}=\mathrm{N}) ; 68.52\left(-\mathrm{CH}_{2}-\mathrm{O}\right) ; 44.12\left(\mathrm{CH}_{2}-\mathrm{N}\right)$ \\
\hline \multirow{2}{*}{ Elemental analysis } & Experimental & $\mathrm{C}=58.32 ; \mathrm{H}=6.24 ; \mathrm{N}=6.25$ \\
& Calculated & $\mathrm{C}=58.92 ; \mathrm{H}=5.98 ; \mathrm{N}=6.44$ \\
\hline
\end{tabular}

\subsection{Electrochemical Measurements}

\subsubsection{Open Circuit Potential (OCP)}

The results of OCP measurements on mild steel corrosion in $1 \mathrm{M} \mathrm{HCl}$ with and without various concentrations of SB are as shown in Figure 1. A relatively steady potential $(\Delta E= \pm 1 \mathrm{mV})$ was reached at about $1000 \mathrm{~s}$ of immersion in all cases. There was initial decrease in potential for mild steel corrosion in $1 \mathrm{M} \mathrm{HCl}$ without the inhibitor (the blank system). This was attributed to dissolution of air oxide film on the mild steel surface [16,17]. A later increase in potential for this system after $50 \mathrm{~s}$ may be due to the formation of insoluble iron (III) oxide [16] on the mild steel surface leading to a more passive state of the steel. Initial increase in potential was observed in the presence of inhibitors followed by a sharp decrease after $75 \mathrm{~s}$.

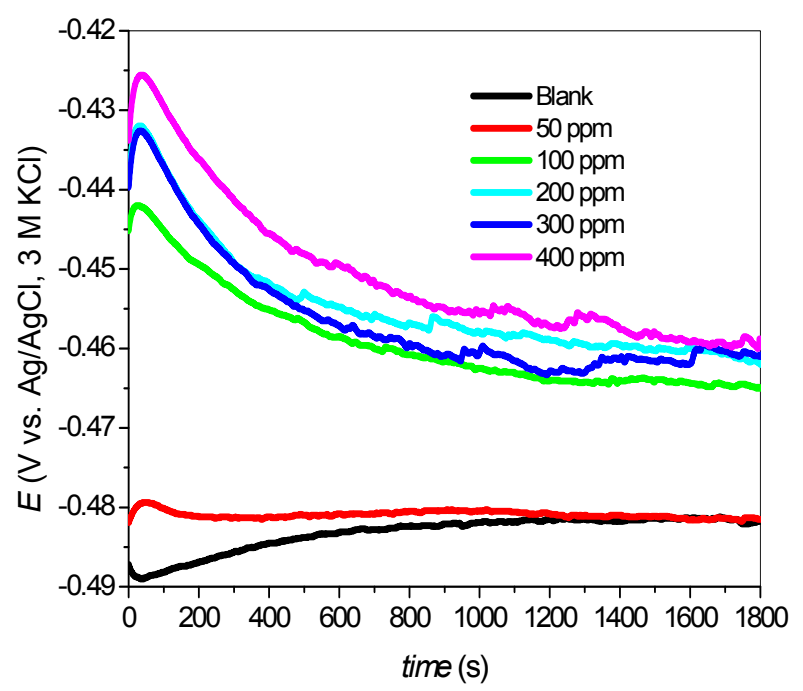

Figure 1. OCP scan for mild steel corrosion in $1 \mathrm{M} \mathrm{HCl}$ with and without various concentrations of SB.

The nature of the OCP in the presence of SB was different from that of the blank. This is due to differences in surface activities on the steel in the absence and presence of the inhibitor. The OCP values for the inhibited systems were generally more positive than that of the uninhibited blank system. This can be attributed to the formation of protective film of the SB inhibitor on the steel surface [18] and suggests the inhibition of anodic dissolution of the steel by the SB under open circuit conditions [19]. Also, the OCP values increase with increase in inhibitor concentrations. This may be 
due to the increased number of inhibitor molecules in the protective layer formed on steel surface leading to thicker protective films. The OCP profile at $50 \mathrm{ppm}$ of SB though reaches plateau at almost the same potential as the uninhibited $1 \mathrm{M} \mathrm{HCl}$ system, the $50 \mathrm{ppm} \mathrm{SB}$ containing electrochemical system obviously has a more positive potential on the average compared to the uninhibited system.

\subsubsection{Potentiodynamic Polarization Measurements}

The polarization measurements were carried out on mild steel electrode immersed in $1 \mathrm{M} \mathrm{HCl}$ with and without various concentrations of SB after $30 \mathrm{~min}$ of immersion. Polarization curves were obtained as the plots of potential against logarithm of current density as presented in Figure 2 . Electrochemical kinetic parameters including the corrosion current density $\left(i_{c o r r}\right)$, corrosion potential $\left(E_{c o r r}\right)$, anodic Tafel slope $\left(\beta_{a}\right)$, cathodic Tafel slope $\left(\beta_{b}\right)$ and percentage inhibition efficiency $(\% I E)$ were determined by linear extrapolations of Tafel lines within the straight-line regions of the polarization curves. These curves exhibit a shift to lower current density in the presence of inhibitor, which implies that $\mathrm{SB}$ reduces the rate of mild steel corrosion in $1 \mathrm{M} \mathrm{HCl}$. The polarization curves are shifted to more positive (noble) values of $E_{c o r r}$ in the presence of SB. This suggests the formation of protective layer of SB on the steel surface. This is also in agreement with the observation during the OCP monitoring. Table 2 shows the kinetic parameters obtained after the linear Tafel fitting. An inhibitor can be regarded as anodic or cathodic type inhibitor if the shift in $E_{c o r r}$ value is greater than $85 \mathrm{mV}$ [20]. As shown in Table 2, the maximum shift in $E_{\text {corr }}$ value in this study was $24 \mathrm{mV}$, which suggests that $\mathrm{SB}$ is a mixed-type inhibitor. That is, it reduces the rate of anodic reaction comprising the mild steel oxidation as well as cathodic reaction, which is hydrogen gas evolution. A closer look at the polarization curves (Figure 2), however, reveals that the anodic inhibiting effect is more pronounced in $1 \mathrm{M} \mathrm{HCl}$, especially between 50 and $300 \mathrm{ppm}$, while at $400 \mathrm{ppm}$ the mix-type inhibition characteristics is more obvious. This fact is also reflected in the relative magnitudes of the differences between the $\beta \mathrm{a}$ of the inhibitor containing and blank systems as well as the corresponding differences in the $\beta_{c}$ values as shown in Table 2. A maximum difference of $49 \mathrm{mV} / \mathrm{dec}$ was observed between the $\beta_{a}$ values in the absence and presence of inhibitor. Such a slight change in the values of $\beta$ a and $\beta_{c}$ upon addition of the inhibitors when compared with the blank suggests that SB adsorbed onto the metal surface and inhibit the corrosion rate without changing the mechanism of the mild steel corrosion in hydrochloric acid [21].

The percentage inhibition efficiency $\left(\% I E_{P}\right)$ was calculated at different concentrations of SB according to the equation:

$$
\% \mathrm{IE}_{\mathrm{P}}=\left(\frac{\mathrm{i}_{\text {corr }}^{0}-\mathrm{i}_{\text {corr }}}{\mathrm{i}_{\text {corr }}}\right) \times 100
$$

where $i_{\text {corr }}^{0}$ and $i_{\text {corr }}$ are the corrosion current density with and without various concentrations of SB, respectively. The values of $\% I E_{P}$ at various concentrations of SB are presented in Table 2 . It is clear that $\% I E_{P}$ increases with increase in concentration of SB with the highest value of $80.6 \%$ obtained at $400 \mathrm{ppm}$ of the inhibitor. 


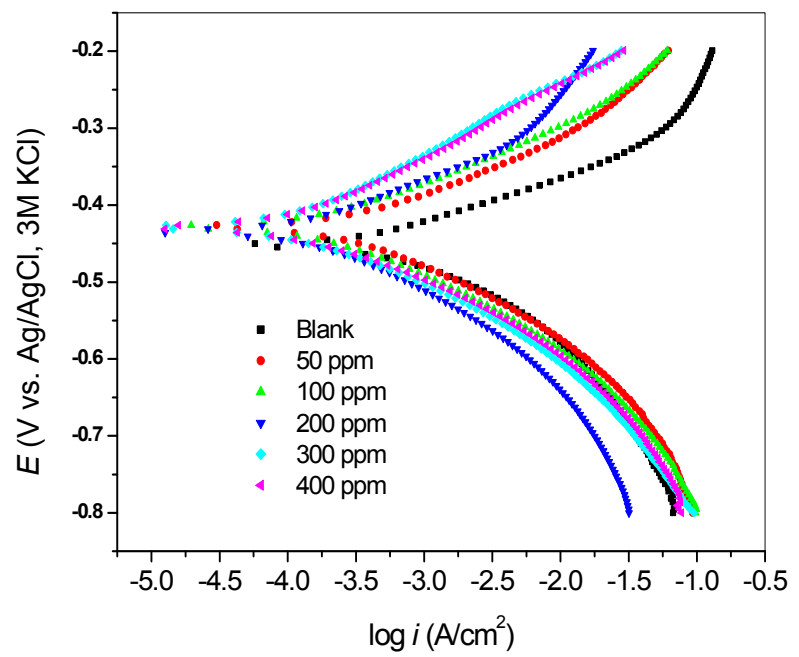

Figure 2. Polarization curves for the corrosion of mild steel in $1 \mathrm{M} \mathrm{HCl}$ with and without various concentrations of SB.

Table 2. Electrochemical kinetic parameters from potentiodynamic polarization experiment.

\begin{tabular}{ccccccc}
\hline Inhibitor Concentration $(\mathbf{p p m})$ & $-\boldsymbol{E}(\mathbf{m V})$ & $\boldsymbol{i}_{\text {corr }}\left(\boldsymbol{\mu A} / \mathbf{c m}^{2}\right)$ & $\boldsymbol{\beta}_{\boldsymbol{a}}(\mathbf{m V} / \mathbf{d e c})$ & $\boldsymbol{\beta}_{\boldsymbol{c}}(\mathbf{m V} / \mathbf{d e c})$ & $\boldsymbol{R}_{\boldsymbol{p}}(\boldsymbol{\Omega})$ & $\boldsymbol{\%} I \boldsymbol{E}$ \\
\hline Blank & 452 & 529.7 & 58 & 102 & 4.832 & - \\
50 & 428 & 310.9 & 71 & 94 & 9.34 & 41.31 \\
100 & 428 & 214.6 & 72 & 97 & 14.16 & 59.49 \\
200 & 434 & 189.6 & 82 & 108 & 20.41 & 64.21 \\
300 & 428 & 172.0 & 107 & 101 & 27.5 & 67.53 \\
400 & 429 & 102.7 & 86 & 73 & 26.44 & 80.61 \\
\hline
\end{tabular}

\subsubsection{Electrochemical Impedance Spectroscopy (Eis) Measurements}

The Nyquist plots obtained from the EIS studies are presented in Figure 3. The Nyquist plots in Figure 3 show a single depressed capacitive arc over the frequency range studied. This is an indication that the dissolution of mild steel in $1 \mathrm{M} \mathrm{HCl}$ is controlled by a single charge transfer process [22]. It was observed that the diameter of the semicircles in the Nyquist plots increases with increase in concentration of the SB inhibitor. Impedance data fitted properly with Randles equivalent circuit of the form $R_{S}\left(R_{c t} Q\right)$, which consists of solution resistance $\left(R_{S}\right)$, in series with the parallel combination of the constant phase element (CPE), denoted as $Q$, and a charge-transfer resistance $\left(R_{c t}\right)$. Due to non-ideal capacitive behavior of the electrode/electrolyte systems investigated in the present study, the CPE was introduced in order to obtain a good agreement between experimental and simulated EIS data. The impedance $(Z)$ of the CPE is defined as:

$$
Z_{C P E}=Q^{-1}(j \omega)^{-n}
$$

where $Q$ is the CPE constant (in $\Omega^{-1} \mathrm{~S}^{\mathrm{n}} \mathrm{cm}^{-2}$ ); $j^{2}=-1$ is the imaginary number; $\omega$ is the angular frequency (in $\operatorname{rads}^{-1}$ ); and $n$ is a CPE exponent, which can be used as a gauge of the heterogeneity or roughness of the surface. 


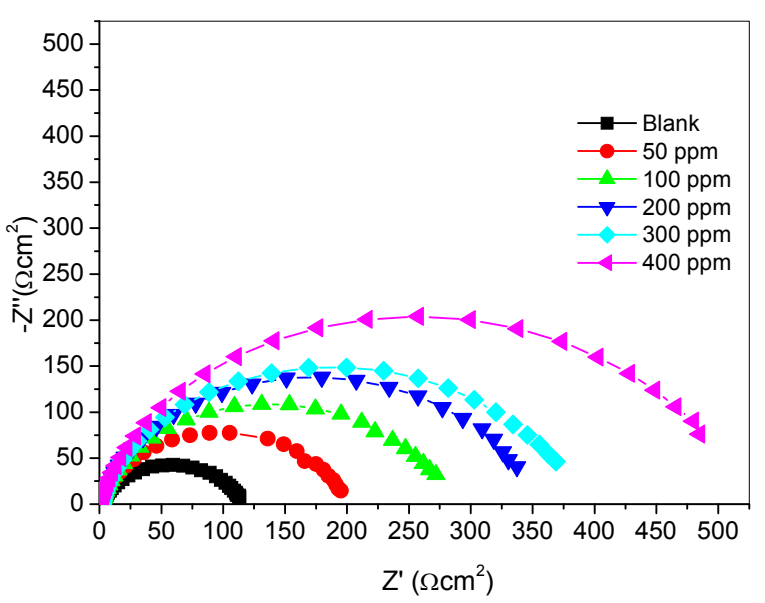

Figure 3. Nyquist plots for mild steel corrosion in $1 \mathrm{M} \mathrm{HCl}$ with and without different concentrations of SB.

The CPE can represent resistance $(n=0, Q=R)$, capacitance $(n=1, Q=C)$, inductance $(n=-1, Q=L)$, or Warburg impedance $(\mathrm{n}=0.5, \mathrm{Q}=\mathrm{W})$. Thus, the closer the value of $\mathrm{n}$ to unity, the better the capacitive behavior of $\mathrm{Q}$. The electrochemical kinetic parameters obtained from the fitting of impedance data are presented in Table 3. Since the CPE exponent, $n$, is close to 1 for the studied system, Q can be assumed to have some capacitive features and referred to as the double-layer capacitance. The percentage inhibition efficiency ( $\left.\% I E_{E I S}\right)$ was calculated by using the equation:

$$
\% I E_{E I S}=\left(\frac{R_{c t}-R_{c t}^{0}}{R_{c t}}\right) \times 100
$$

where $R_{c t}^{0}$ and $R_{c t}$ are the charge transfer resistances with and without various concentrations of SB inhibitor, respectively. As shown in Table 3, \%IE EIS increases with increase in concentration of SB. This confirms the inhibition potency of SB against mild steel corrosion in $1 \mathrm{M} \mathrm{HCl}$. There is an increase in the values of $R_{c t}$ as the concentration of SB increases. This is attributed to an increase in the interface between the metal surface and the aggressive solution due to increase in the area of the adsorption film formed on the metal surface. According to the Helmholtz model [23], Q is expressed as:

$$
Q=\frac{\varepsilon^{0} \varepsilon}{d} S
$$

where $\varepsilon^{0}$ is the permittivity of the vacuum; $\varepsilon$ is the dielectric constant of the medium; $d$ is the thickness of the film and $\mathrm{S}$ is the surface area of the electrode. The decrease in values of $Q$ as the concentration of SB increases may be due to an increase in the area of the adsorption film, which corresponds to the decrease in the exposed electrode surface area $(S)$, or an increase in the thickness of the adsorbed protective layer $(d)$ or a decrease in the medium dielectric constant $(\varepsilon)$. One or more of these result in the observed decrease in the values of $Q$ in accordance to Equation (4) above.

The variations of percentage inhibition efficiency with concentrations of SB are plotted in Figure 4. There is a good agreement between the values obtained for the percentage inhibition efficiency from the polarization and impedance techniques. It is worthy of mention that the studied compound (SB) when compared with some previously reported organic inhibitors exhibits similar or relatively better inhibition performance for mild steel corrosion in $1 \mathrm{M} \mathrm{HCl} \mathrm{[24-26].}$ 
Table 3. Fitted parameters from electrochemical impedance spectroscopy.

\begin{tabular}{cccccc}
\hline Inhibitor Concentration $(\mathbf{p p m})$ & $\boldsymbol{R}_{\boldsymbol{s}}\left(\mathbf{\Omega c m}^{-\mathbf{2}}\right)$ & $\boldsymbol{R}_{\boldsymbol{c t}}\left(\mathbf{\Omega} \mathbf{c m}^{-\mathbf{2}}\right)$ & $\boldsymbol{Q}_{\boldsymbol{1}}\left(\mathbf{Y}_{\mathbf{0}}\right)\left(\boldsymbol{\mu} \mathbf{F} \mathbf{c m}^{-\mathbf{2}}\right)$ & $\boldsymbol{n}$ & $\boldsymbol{\%} \boldsymbol{I E}$ \\
\hline BIS \\
\hline 50 & 1.947 & 115.30 & 145.00 & 0.8027 & - \\
100 & 2.570 & 193.00 & 85.58 & 0.8756 & 40.26 \\
200 & 1.808 & 274.10 & 82.21 & 0.8651 & 57.94 \\
300 & 1.937 & 343.00 & 71.67 & 0.8736 & 66.38 \\
400 & 1.754 & 374.00 & 64.57 & 0.8707 & 69.17 \\
& 1.504 & 506.00 & 61.56 & 0.8718 & 77.21 \\
\hline
\end{tabular}

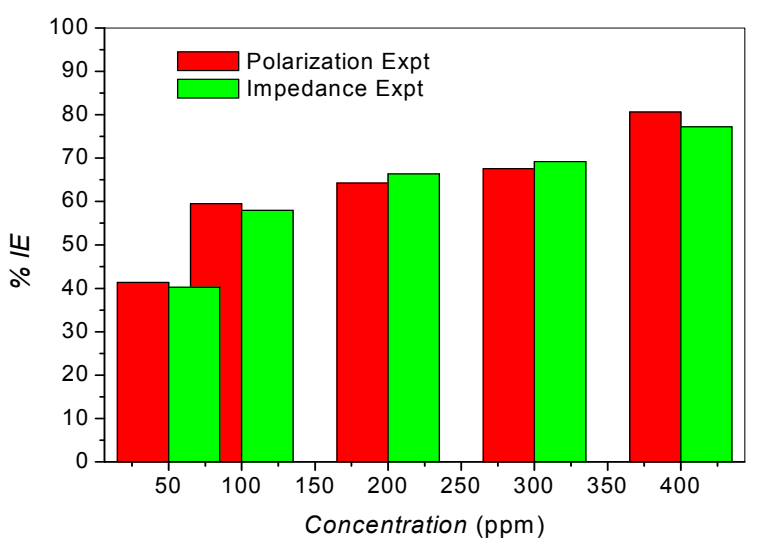

Figure 4. Variation of percentage inhibition efficiency $(\% I E)$ with concentration of SB for both polarization and impedance experiments.

\subsection{Adsorption Isotherms}

Important information on the adsorption behavior of an inhibitor on a metal surface can be obtained by fitting the experimental data into appropriate adsorption isotherms. The adsorption of inhibitor on metal/solution interface may occur through the displacement of water molecules by the inhibitor molecules [27] in accordance to the reaction equation:

$$
\operatorname{Inh}_{(\text {sol })}+x \mathrm{H}_{2} \mathrm{O}_{(\mathrm{ads})} \leftrightarrow \operatorname{Inh}_{(\mathrm{ads})}+x \mathrm{H}_{2} \mathrm{O}_{(\mathrm{sol})}
$$

where, $x$, the mole ratio, is the number of water molecules replaced by one molecule of organic inhibitor. The surface coverage, $\theta$, was calculated from the percentage inhibition efficiency $(\theta=\% I E / 100)$, obtained from both polarization and impedance measurements. The experimental data obtained fitted well with the Langmuir adsorption isotherm represented by the equation:

$$
\frac{C_{i n h}}{\theta}=\frac{1}{K_{a d s}}+C_{i n h}
$$

where $C_{i n h}$ is the concentration of the inhibitor and $K_{a d s}$ is the equilibrium adsorption constant. The plots of $C_{i n h} / \theta v s C_{i n h}$ (Figure 5) gave straight lines with strong linear correlation coefficients. 


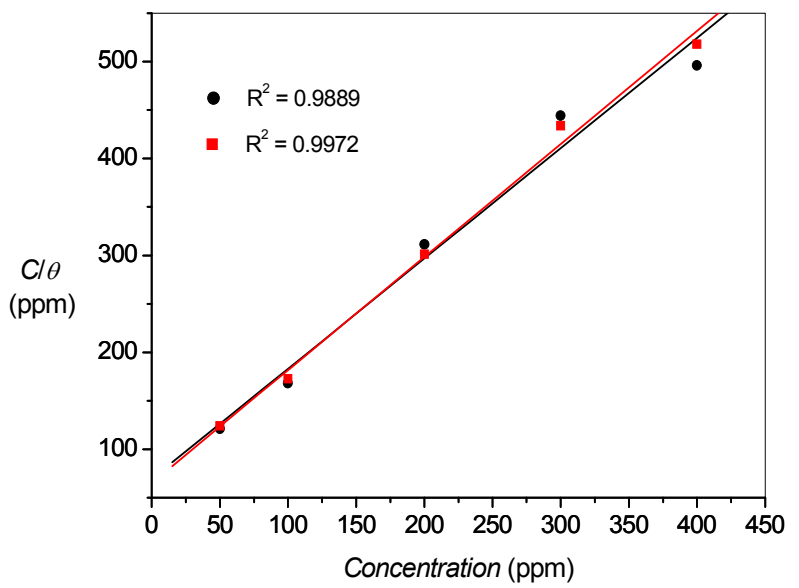

Figure 5. Langmuir adsorption isotherms of SB adsorption on mild steel surface from (•) polarization and $(\bullet)$ impedance experiments.

The change in free energy of adsorption $\left(\Delta G_{a d s}\right)$ was calculated from the relation:

$$
\Delta G_{a d s}=-R T \ln \left(55.5 K_{a d s}\right)
$$

where $R$ is gas constant; $T$ is absolute temperature and the constant 55.5 is the molar concentration of water. The values of $K_{a d s}$ and $\Delta G_{a d s}$ are presented in Table 4 . The negative value of $\Delta G_{a d s}$ implies that the adsorption process is spontaneous. The magnitude of $\Delta G_{a d s}$ is usually used to predict the nature of adsorption, whether it is physisorption or chemisorption. A value of $\Delta G_{a d s}$ around $-20 \mathrm{~kJ} / \mathrm{mol}$ or less negative has been attributed to electrostatic interactions between the charged inhibitor molecules and the charged metal surface (physisorption), while values around $-40 \mathrm{~kJ} / \mathrm{mol}$, or larger negative values, involve charge sharing or charge transfer from organic molecules to the metal surface to form coordinate bond (chemisorption) [28]. The magnitudes of $\Delta G_{a d s}$ obtained in the present study suggest that the adsorption of SB on mild steel surface is a combination of both physisorption and chemisorption processes.

Table 4. Adsorption constant and change in free energy of adsorption of SB on mild steel surface from polarization and impedance experiments at $303 \mathrm{~K}$.

\begin{tabular}{ccc}
\hline & $\boldsymbol{K}_{\text {ads }}\left(\times \mathbf{1 0}^{-\mathbf{3}}\right)$ & $-\Delta \boldsymbol{G}_{\text {ads }}(\mathbf{k J} / \mathbf{m o l})$ \\
\hline Polarization Expt. & 6.47 & 31.71 \\
Impedance Expt. & 6.89 & 31.86 \\
\hline
\end{tabular}

\subsection{Ultraviolet-Visible and Raman Spectroscopic Studies}

UV-vis and Raman spectroscopic analyses were carried out on pure SB and the resulting solution of SB after five days of mild steel immersion. Comparison of the spectroscopic features of pure SB and $\mathrm{SB}$ with mild steel can provide information about possible formation of Fe/SB complex. The UV-vis spectrum of SB solution (Figure 6) shows two absorption peaks, at $310 \mathrm{~nm}$ and $234 \mathrm{~nm}$, corresponding to $n \rightarrow \pi^{*}$ transition, $\pi \rightarrow \pi^{*}$ transition and intermolecular charge transfer. After mild steel immersion, the maximum absorption peak seems to be unaffected as it re-appeared at $309 \mathrm{~nm}$. However, there is a slight blue shift of the peak at $234 \mathrm{~nm}$ to $229 \mathrm{~nm}$. This may be attributed to the formation of coordinate bonds between $\mathrm{Fe}$ and $\mathrm{SB}$. 


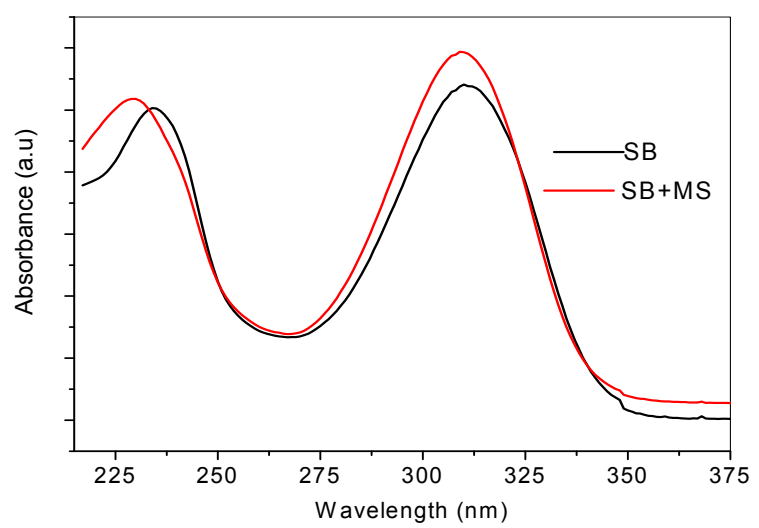

Figure 6. UV-Vis spectra of pure SB solution (black, SB) and SB solution after mild steel immersion (red, SB+MS).

The Raman spectroscopic analysis of possible formation $\mathrm{Fe} / \mathrm{SB}$ complex was carried out by investigating the change in prominent Raman bands between $200 \mathrm{~cm}^{-1}$ and $2000 \mathrm{~cm}^{-1}$ after mild steel immersion in SB solution. As shown in Figure 7, in the pure $\mathrm{SB}$, a strong band at $371 \mathrm{~cm}^{-1}$ is assigned to aliphatic $\mathrm{CC}$ chains in the molecule, while a medium peak, characteristic of C-O-C band appears at $978 \mathrm{~cm}^{-1}$, coupled with its asymmetric band at $1074 \mathrm{~cm}^{-1}$. Aromatic $\mathrm{CC}$ bands of medium intensity appear at $1173 \mathrm{~cm}^{-1}$ and $1451 \mathrm{~cm}^{-1}$. Two strong bands appear at $1602 \mathrm{~cm}^{-1}$ and $1674 \mathrm{~cm}^{-1}$ which may be due to $\mathrm{C}=\mathrm{N}$ functional group. The band at $1732 \mathrm{~cm}^{-1}$ is of medium intensity and it is attributed to $\mathrm{C}=\mathrm{O}$. After mild steel immersion, more bands appear in the region below $500 \mathrm{~cm}^{-1}$. The strong bands at $382 \mathrm{~cm}^{-1}$ and $458 \mathrm{~cm}^{-1}$ are of special interest and can be assigned to Fe-O, suggesting bond formation between SB and Fe through the $\mathrm{sp}^{2}$ oxygen. Other bands have also shifted correspondingly after mild steel immersion in SB. Most of the bands shifted to higher wavenumbers after mild steel immersion. This includes the bands for $\mathrm{C}=\mathrm{N}$ functional groups.

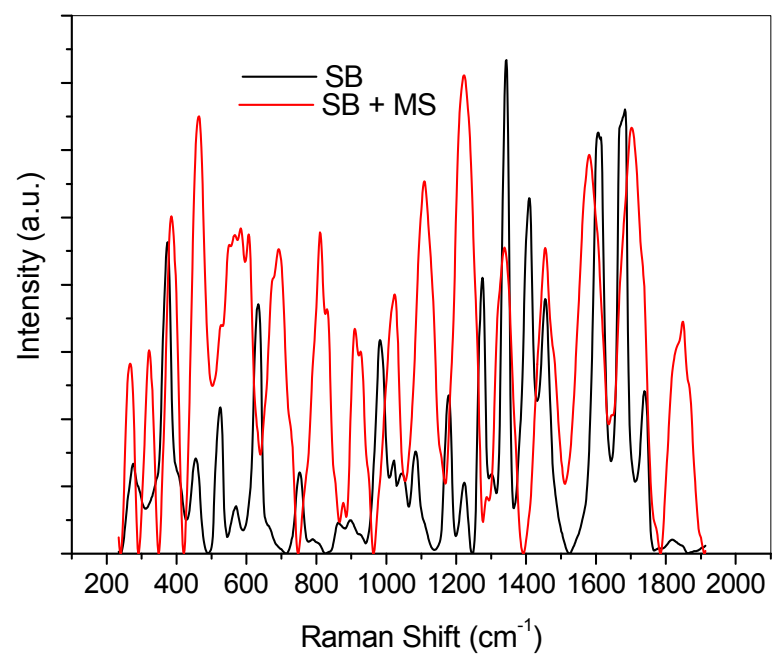

Figure 7. Raman spectra of pure SB solution (black, SB) and SB solution after mild steel immersion (red, SB + MS). 


\subsection{Quantum Chemical Calculations}

The gas phase optimized structure of SB with atom labels is shown in Figure 8. SB is expected to be a symmetrical molecule but the optimized structure shows that there is extension of $\pi$-conjugation to the $\mathrm{O} 27$ atom of the $-\mathrm{OH}$ group, whereas this is not observed on the similar oxygen atom $\mathrm{O} 13$ of the $-\mathrm{OH}$ group on the other end of the molecule. This non-uniform distribution of electron density makes the molecule to be unsymmetrical. Relevant quantum chemical parameters of the optimized structure are listed in Table 5. Adsorption of an inhibitor on a metal surface is often explained based on donor-acceptor phenomenon between the inhibitor and metal atom. The energy of the highest occupied molecular orbitals $($ ЕНОмо $)$ is associated with the tendency of an inhibitor molecule to donate its least stable electron(s) to the appropriate vacant orbitals of the metal atom. On the other hand, the energy of the lowest unoccupied molecular orbitals $\left(E_{L U M O}\right)$ informs the tendency of the inhibitor molecule to accept charges from the metal atom towards back-bonding. The higher the Eномо, the higher the possibility of forward donation of charges to the metal, and the lower the $E_{L U M O}$, the better the chances of back-donation of charges. The results in Table 5 show that the values of $E_{H O M O}, E_{L U M O}$ and energy gap $\left(\triangle E_{L U M O-H O M O}\right)$, the ionization potential $\left(\mathrm{I}=-E_{\text {HOMO }}\right)$ and the electron affinity $\left(\mathrm{A}=-E_{L U M O}\right)$ of SB are within the range of values that have been reported for some other Schiff bases that had also been adjudged good corrosion inhibitors [29]. SB has a reasonably high dipole moment, which suggests that it has the potential to interact with metal atom or ions in aqueous system. The results of the chemical potential $(\mu)$, hardness $(\eta)$ and electrophilicity $(\omega)$ as shown in Table 5 reveal that SB has a potential to react with $\mathrm{Fe}$ in the mild steel thereby protecting the steel surface against corrosion. The value obtained for fraction of electrons transferred $(\Delta N)$ from the inhibitor molecule to the metal surface confirms the possibility of charge transfers from SB to the mild steel.

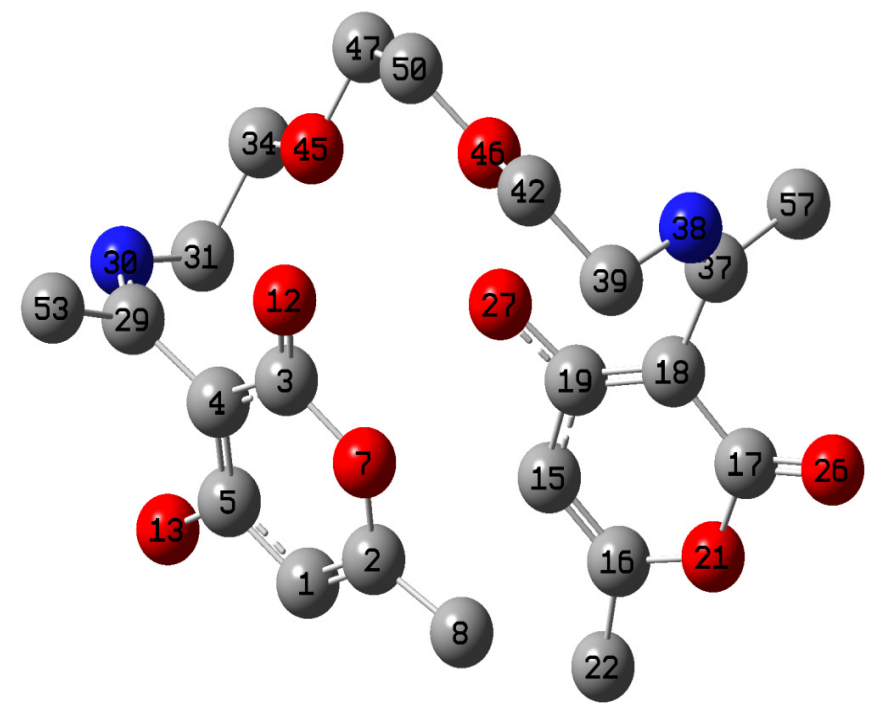

Figure 8. Optimized structure of SB showing only non-hydrogen atoms with atomic numbering. 
Table 5. Some gas-phase quantum chemical parameters of SB calculated at B3LYP/6-31G(d) level.

\begin{tabular}{cc}
\hline Parameter & Value \\
\hline Total energy $(\mathrm{au})$ & -1566.4527 \\
$E_{\text {HОмO }}(\mathrm{eV})$ & -5.99 \\
$E_{L U M O}(\mathrm{eV})$ & -1.46 \\
$\Delta E_{L U M O-H O M O}$ & 4.53 \\
$I$ & 5.99 \\
$A$ & 1.46 \\
Dipole moment $($ Debye $)$ & 5.69 \\
Chemical potential, $\mu(\mathrm{eV})$ & -3.72 \\
Hardness, $\eta(\mathrm{eV})$ & 2.26 \\
Electrophilicity, $\omega(\mathrm{eV})$ & 3.06 \\
$\Delta N$ & 0.72 \\
$\Delta E(\mathrm{eV})$ & -0.57 \\
\hline
\end{tabular}

The change in energy $(\Delta E)$ following charge transfer implies that the charge transfer from SB to mild steel followed by back donation from mild steel to the inhibitor is energetically favorable. The HOMO and LUMO graphic surfaces (Figure 9) are distributed around the unsaturated ring of the dehydroacetic acid with the HOMO surface being around the ring with the unsaturated $-\mathrm{OH}$ group and the LUMO surface on the ring that has no $\pi$-conjugation to the $-\mathrm{OH}$. The Mulliken atomic charges of SB are displayed on the atoms in the optimized structure (Figure 10). There are quite a number of atoms with negative Mulliken charges, which implies that SB has potential atoms that can interact with relatively positive centers on the mild steel surface.

The Fukui functions $(f(\mathrm{r}))$ are often used as indices of local reactivity to analyze the active atomic sites in inhibitor molecules [30,31]. The Fukui functions $(f(\mathrm{r}))$ measure the change in the electron density of an $\mathrm{N}$ electron system upon addition $\left(f^{+}(\mathrm{r})\right)$ or removal $(f(\mathrm{r}))$ of an electron [32]. Atom condensed Fukui functions using the Mulliken population analysis (MPA) and the finite difference (FD) approximations approach introduced by Yang and Mortier [33] were calculated using the equations:

$$
\begin{aligned}
& f_{k}^{+}=\rho_{k(N+1)}(r)-\rho_{k(N)}(r) \\
& f_{k}^{-}=\rho_{k(N)}(r)-\rho_{k(N-1)}(r)
\end{aligned}
$$

where $\rho_{k(N+1)}, \rho_{k(N)}$ and $\rho_{k(N-1)}$ are the electron densities of the $(N+1)$-, $N$ - and $(N-1)$ - electron systems, respectively, and approximated by Mulliken gross charges; $f^{+}$and $f$ are the Fukui indices condensed on atom $k$ and measure its electrophilic and nucleophilic tendencies, respectively. The Fukui indices are listed in Table 6 for selected non-hydrogen atoms in SB. The atomic labels employed in Table 6 are the same as those displayed in Figure 8. The most susceptible sites for nucleophilic attacks are O45, C31, C47 and C50, while the most susceptible sites for electrophilic attack are C39, O45, C50, C47 and $\mathrm{C} 31$ in that order. 

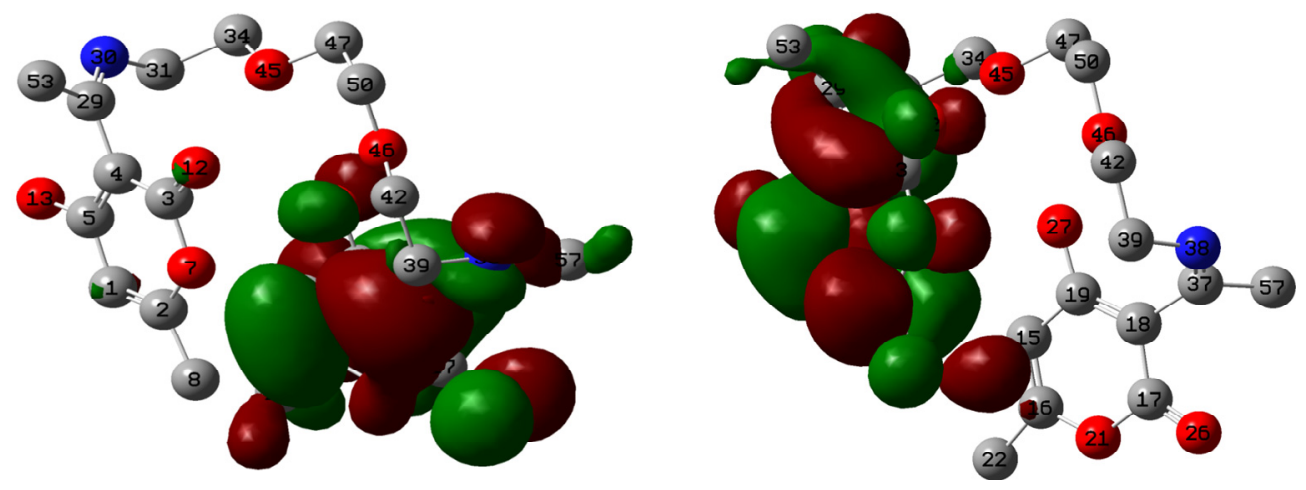

Figure 9. HOMO and LUMO surfaces of SB at an isosurface value of 0.02.

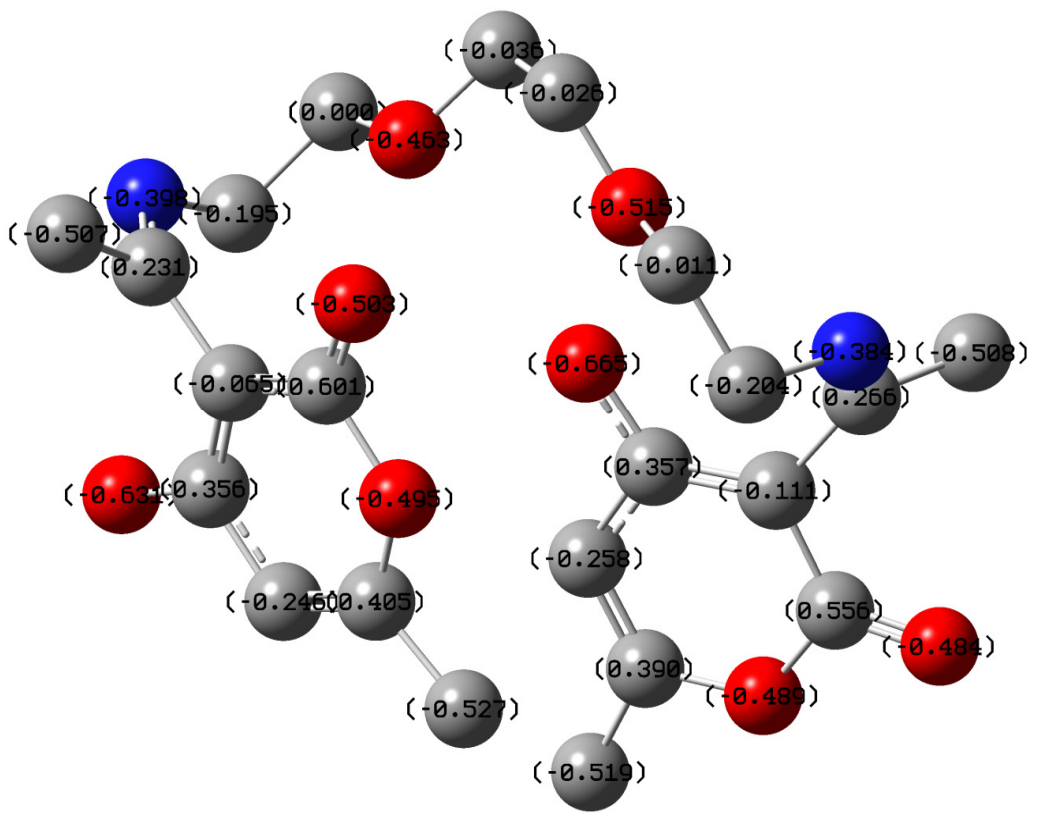

Figure 10. Mulliken atomic charges of atoms in the optimized structure of SB.

Table 6. Fukui indices for non-hydrogen selected atoms in SB molecule.

\begin{tabular}{cccc}
\hline Atom & $\boldsymbol{f}^{+}$ & Atom & $\boldsymbol{f}^{\mathbf{c}}$ \\
\hline $\mathrm{C} 1$ & 0.0013 & $\mathrm{C} 8$ & 0.0022 \\
$\mathrm{C} 8$ & 0.0098 & $\mathrm{C} 22$ & 0.0085 \\
$\mathrm{C} 15$ & 0.0104 & $\mathrm{C} 29$ & 0.0054 \\
$\mathrm{C} 22$ & 0.0072 & $\mathrm{C} 31$ & 0.0102 \\
$\mathrm{C} 31$ & 0.0182 & $\mathrm{C} 34$ & 0.0097 \\
$\mathrm{C} 34$ & 0.0076 & $\mathrm{C} 37$ & 0.0005 \\
$\mathrm{C} 39$ & 0.0040 & $\mathrm{C} 39$ & 0.0163 \\
$\mathrm{C} 42$ & 0.0081 & $\mathrm{C} 42$ & 0.0077 \\
$\mathrm{O} 45$ & 0.0215 & O45 & 0.0135 \\
O46 & 0.0078 & O46 & 0.0088 \\
$\mathrm{C} 47$ & 0.0127 & $\mathrm{C} 47$ & 0.0114 \\
$\mathrm{C} 50$ & 0.0102 & $\mathrm{C} 50$ & 0.0136 \\
$\mathrm{C} 53$ & 0.0076 & $\mathrm{C} 53$ & 0.0042 \\
C57 & 0.0052 & $\mathrm{C} 57$ & 0.0072 \\
\hline
\end{tabular}




\section{Experimental Section}

\subsection{Materials}

All reagents and solvents were of analytical grade and were used without further purification. The experiments were performed on mild steel samples with the chemical composition (wt \%) $\mathrm{C}=0.17$, $\mathrm{Mn}=0.46, \mathrm{Si}=0.26, \mathrm{~S}=0.017, \mathrm{P}=0.019$, and balance Fe. For all electrochemical studies, mild steel coupons were cut into $1 \mathrm{~cm} \times 1 \mathrm{~cm}$ dimensions and embedded in a Teflon holder using epoxy resin, exposing only $1 \mathrm{~cm}^{2}$ surface area. Prior to each measurement, mild steel surface was mechanically abraded on Struers MD PianoTM 220 (size: 200 dia) mounted on Struers LaboPol-1 machine to remove traces of epoxy resin from the surface. The surface was then polished with SiC papers of various grit sizes ranging from 600 to 1200 to achieve a finely ground surface then washed with water followed by acetone and then water again, and finally wiped with clean tissue paper and air-dried. Mild steel specimens were used immediately after surface preparation.

\subsection{Chemicals and Instrumentation}

3-acetyl-4-hydroxy-6-methyl- $(2 \mathrm{H})$ pyran-2-one and 2,2'-(ethylenedioxy)diethylamine were used as supplied by Fluka. Elemental analyses of $\mathrm{C}, \mathrm{H}$ and $\mathrm{N}$ were performed by using Carlo Erba Elemental analyzer EA 1108. Melting point was taken in open capillaries on a melting point apparatus model no 125. IR spectra were recorded on a Perkin Elmer Spectrum 100. 1H and 13C NMR spectra were obtained from a Bruker AV $500 \mathrm{MHz}$ for $1 \mathrm{H}$ and $125 \mathrm{MHz}$ for 13C using a $5 \mathrm{~mm}$ Quadra Nuclei Probe (QNP). UV-Vis spectra were recorded on Cary 300 UV-Vis by Agilent Technologies. Raman spectra were obtained from Xplora Raman spectrometer from Horiba Scientific.

\subsection{Synthesis of 3-acetyl-4-hydroxy-6-methyl-(2H) pyran-2-one Schiff base (SB)}

A solution of 3-acetyl-4-hydroxy-6-methyl-(2H) pyran-2-one (3.36 g, $0.02 \mathrm{~mol})$ in $20 \mathrm{~mL}$ ethanol was mixed with a solution of 2,2'-(ethylendioxy) diethylamine in $20 \mathrm{~mL}$ ethanol. The equation of reaction is as shown in Equation (10):<smiles>CC(=O)c1c(O)cc(C)oc1=O</smiles>

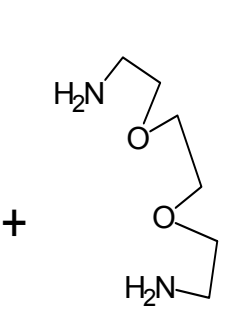

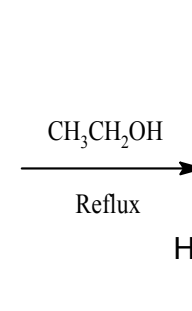

The mixture was refluxed for $3 \mathrm{~h}$, and the resulting solution was chilled to $-10{ }^{\circ} \mathrm{C}$ to obtain a whitish product which was filtered, dried and recrystallized in water.

\subsection{Electrochemical Measurements}

All electrochemical measurements were carried out on the Autolab PGSTAT 302N obtained from Metrohm, equipped with a three-electrode system. $\mathrm{Ag} / \mathrm{AgCl}$ with $3 \mathrm{M} \mathrm{KCl}$ was used as the reference electrode, while platinum rod was used as the counter electrode. 
The system was allowed to reach the steady open circuit potential (OCP) before each electrochemical measurement. The OCP measurements were carried out for $30 \mathrm{~min}$ in the aggressive solutions with and without various concentrations of SB. The systems were confirmed to have reached OCP before 30 min with less than $\pm 10 \mathrm{mV}$ change in potential. The potentiodynamic polarization tests were performed after $30 \mathrm{~min}$ of mild steel immersion in the aggressive solutions by sweeping the potential between $-200 \mathrm{mV}$ and $-800 \mathrm{mV}$ versus $\mathrm{Ag} / \mathrm{AgCl}, 3 \mathrm{M} \mathrm{KCl}$ reference electrode potential at the scan rate of $1 \mathrm{mV} / \mathrm{s}$. Electrochemical impedance spectroscopy measurements were carried out after $30 \mathrm{~min}$ of mild steel immersion in the aggressive solution with and without various concentrations of the inhibitor. The electrochemical impedance spectroscopy measurements were conducted at the OCP by analyzing the frequency response of the electrochemical system in the range of $100 \mathrm{kHz}$ to $1 \mathrm{~Hz}$ at $5 \mathrm{mV}$ amplitude. All electrochemical experiments were conducted under unstirred conditions at $303 \mathrm{~K}$.

\subsection{Quantum Chemical Calculations}

All quantum chemical calculations were carried out using the DFT method involving the Becke 3-Parameter exchange functional together with the Lee-Yang-Parr correlation functional (B3LYP) [34,35] and 6-31G(d) basis set. SB was modeled with Gaussview 5.0 software to obtain the initial geometries. Gas phase geometry optimization was carried out using Gaussian 09W D.01 software [36].

\section{Conclusions}

The new Schiff base (SB) synthesized from the condensation of 3-acetyl-4-hydroxy-6-methyl(2H)pyran-2-one and 2,2'-(ethylenedioxy)diethylamine showed corrosion inhibition potency for the protection of mild steel in $1 \mathrm{M} \mathrm{HCl}$, as confirmed by potentiodynamic polarization and electrochemical impedance spectroscopy experiments. SB was found to be a mixed-type inhibitor and its inhibition property was associated with its spontaneous adsorption onto mild steel surface via both physisorption and chemisorption. The experimental data fitted Langmuir adsorption isotherm. UV-vis and Raman spectroscopic analyses revealed the possibilities of chemical interactions and bond formation between mild steel and SB. Quantum chemical calculations suggested the possible sites for nucleophilic and electrophilic attack on SB.

\section{Acknowledgments}

Eno E. Ebenso gratefully acknowledges the National Research Foundation (NRF) of South Africa for incentive funding for rated researchers. A.S.A. thanks the NRF/Sasol Inzalo foundation for financial support and NWU for postdoctoral fellowship. L.O.O. acknowledges NRF/Sasol Inzalo foundation for funding support towards his $\mathrm{PhD}$ studies.

\section{Author Contributions}

All the authors have equally contributed to the manuscript. 


\section{Conflicts of Interest}

The authors declare no conflict of interest.

\section{References}

1. De la Fuente, D.; Diaz, I.; Simancas, J.; Chico, B.; Morcillo, M. Long-term atmospheric corrosion of mild steel. Corros. Sci. 2011, 53, 604-617.

2. Ulaeto, S.B.; Ekpe, U.J.; Chidiebere, M.A.; Oguzie, E.E. Corrosion inhibition of mild steel in hydrochloric acid by acid extracts of Eichhornia crassipes. Int. J. Mat. Chem. 2012, 2, 158-164.

3. Guzman-Lucero, D.; Olivares-Xometl, O.; Martinez-Palou, R.; Likhanova, N.V.; Dominguez-Aguilar, M.A.; Garibay-Febles, V. Synthesis of selected vinylimidazolium ionic liquids and their effectiveness as corrosion inhibitors for carbon steel in aqueous sulfuric acid. Ind. Eng. Chem. Res. 2011, 50, 7129-7140.

4. Sastri, V.S. Corrosion Inhibitors Principles and Applications; Jonh Wiley \& Sons: New York, NY, USA, 1998.

5. Mishra, M.; Tiwari, K.; Singh, A.K.; Singh, V.P. Synthesis, structural and corrosion inhibition studies on $\mathrm{Mn}(\mathrm{II}), \mathrm{Cu}(\mathrm{II})$ and $\mathrm{Zn}(\mathrm{II})$ complexes with a Schiff base derived from 2-hydroxypropiophenone. Polyhedron 2014, 77, 57-65.

6. Quan, Z.; Chen, S.; Li, S. Protection of copper corrosion by modification of self-assembled films of Schiff bases with alkanethiol. Corros. Sci. 2001, 43, 1071-1080.

7. Battaini, G.; Monzani, E.; Casella, L.; Santagostini, L.; Pagliarin, R. Inhibition of the catecholase activity of biomimetic dinuclear copper complexes by kojic acid. J. Biol. Inorg. Chem. 2000, 5, 262-268.

8. Puerta, D.T.; Cohen, S.M. Examination of novel zinc-binding groups for use in matrix metalloproteinase inhibitors. Inorg. Chem. 2003, 42, 3423-3430.

9. Rao, P.V.; Narasaiah, A.V. Synthesis, characterization and biological studies of oxovanadium(IV), manganese(II), iron(II), cobalt(II), nickle(II) and copper(II) complexes derived from a quadridentate ligand. Indian J. Chem. A 2003, 42, 1896-1899.

10. Chalaca, M.Z.; Figueroa-Villar, J.D.; Ellena, J.A.; Castellano, E.E. Synthesis and structure of cadmium and zinc complexes of dehydroacetic acid. Inorg. Chem. Acta 2002, 328, 45-52.

11. Fouad, D.M.; Bayoumi, A.; El-Gahami, M.A.; Ibrahim, S.A.; Hammam, A.M. Synthesis and thermal studies of mixed ligand complexes of $\mathrm{Cu}(\mathrm{II}), \mathrm{Co}(\mathrm{II}), \mathrm{Ni}(\mathrm{II})$ and $\mathrm{Cd}(\mathrm{II})$ with mercaptotriazoles and dehydroacetic acid. Natural Science 2010, 2, 817-827.

12. Chitrapriya, N.; Mahalingam, V.; Zeller, M.; Jayabalan, R.; Swaminathan, K.; Natarajan, K. Synthesis, crystal structure and biological activities of dehydroacetic acid complexes of $\mathrm{Ru}(\mathrm{II})$ and $\mathrm{Ru}(\mathrm{III})$ containing PPh3/AsPh3. Polyhedron 2008, 27, 939-946.

13. Asegbeloyin, J.N.; Ujam, O.T.; Ngige, C.M.; Onwukeme, V.I.; Groutso, T. Crystal structure of N'-[(1E)-1-(6-methyl-2,4-dioxo-3,4-dihydro-2H-pyran-3-ylidene)ethyl]benzenesulfonohydr-azide. Acta Cryst. 2014, E70, 01179-01180.

14. Kubaisi, A.A.; Ismail, K.Z. Nickel(II) and palladium(II) chelates of dehydroacetic acid Schiff bases derived from thiosemicarbazide and hydrazinecarbodithioate. Can. J. Chem. 1994, 72, 1785-1788. 
15. Asegbeloyin, J.N.; Babahan, I.; Ukwueze, N.N.; Oruma, U.S.; Poyrazoglu, E.C.; Eze, U.F. Synthesis, characterization and antimicrobial activity of 3-acetyl-4-hydroxy-6-methyl-(2H)pyran2-one Schiff base with 2,2'-(ethylenedioxy)diethylamine and its $\mathrm{Co}(\mathrm{II}), \mathrm{Ni}$ (II) and $\mathrm{Cu}(\mathrm{II})$ complexes. Asian J. Chemistry 2015, 27, in press.

16. Sudheer; Quraishi, M.A. 2-Amino-3,5-dicarbonitrile-6-thio-pyridines: New and effective corrosion inhibitors for mild steel in $1 \mathrm{M} \mathrm{HCl}$. Ind. Eng. Chem. Res. 2014, 53, 2851-2859.

17. Rammelt, U.; Koehler, S.; Reinhard, G. Electrochemical characterization of the ability of dicarboxylic acid salts to the corrosion inhibition of mild steel in aqueous solutions. Corros. Sci. 2011, 53, 3515-3520.

18. Sheriff, E.M.; Erasmus, R.M.; Comins, J.D. In situ Raman spectroscopy and electrochemical techniques for studying corrosion and corrosion inhibition of iron in sodium chloride solutions Electrochimica. Acta 2010, 55, 3657-3663.

19. El Adnani, Z.; Mcharfi, M.; Sfaira, M.; Benzakour, M.; Benjelloun, A.T.; Ebn Touhami, M.; Hammouti, B.; Taleb, M. DFT study of 7-R-3methylquinoxalin-2(1H)-ones $(\mathrm{R}=\mathrm{H}$; $\mathrm{CH} 3$; $\mathrm{Cl})$ as corrosion inhibitors in hydrochloric acid. Int. J. Electrochem. Sci. 2012, 7, 6738-6751.

20. Satapathy, A.K.; Gunasekaran, G.; Sahoo, S.C.; Kumar, A; Rodrigues, P.V. Corrosion inhibition by Justicia gendarussa plant extract in hydrochloric acid solution. Corros. Sci. 2009, 51, 2848-2856.

21. Abdallah, M.; Asghar, B.H.; Zaafarany, I.; Fouda, A.S. The inhibition of carbon steel corrosion in hydrochloric acid solution using some phenolic compounds. Int. J. Electrochem. Sci. 2012, 7 , 282-304.

22. Daoud, D.; Douadi, T.; Issaadi, S.; Chafaa, S. Adsorption and corrosion inhibition of new synthesized thiophene Schiff base on mild steel $\mathrm{X} 52$ in $\mathrm{HCl}$ and $\mathrm{H}_{2} \mathrm{SO}_{4}$ solutions. Corros. Sci. 2014, 79, 50-58.

23. Benabdellah, M.; Ousslim, A.; Hammouti, B.; Elidrissi, A.; Aouniti, A.; Dafali, A.; Bekkouch, K.; Benkaddour, M.J. The effect of poly(vinyl caprolactone-co-vinyl pyridine) and poly(vinyl imidazol-co-vinyl pyridine) on the corrosion of steel in $\mathrm{H}_{3} \mathrm{PO}_{4}$ media. Appl. Electrochem. 2007, 37, 819-826.

24. Chakravarthy, M.P.; Mohana, K.N.; Kumar, C.B.P. Study of adsorption properties and inhibition of mild steel corrosion in hydrochloric acid media by water soluble composite poly (vinyl alcohol-omethoxy aniline). J. Assoc. Arab Univ. Basic Appl. Sci. 2014, 16, 74-82.

25. Chakravarthy, M.P.; Mohana, K.N.; Kumar, C.B.P. Corrosion inhibition effect and adsorption behaviour of nicotinamide derivatives on mild steel in hydrochloric acid solution. Int. J. Ind. Chem. 2014, 5, 1-21.

26. Abd-Elaal, A.A.; Aiad, I.; Shaban, S.M.; Tawfik, S.M.; Atef, S. Synthesis and Evaluation of Some Triazole Derivativesas Corrosion Inhibitors and Biocides. J. Surfact. Deterg. 2014, 17, 483-491.

27. John, S.; Kuruvilla, M.; Joseph, A. Adsorption and inhibition effect of methyl carbamate on copper metal in $1 \mathrm{~N} \mathrm{HNO}_{3}$ : An experimental and theoretical study. RSC Adv. 2013, 3, 8929-8938.

28. Murulana, L.C.; Singh, A.K.; Shukla, S.K.; Kabanda, M.M.; Ebenso, E.E. Experimental and quantum chemical studies of some bis(trifluoromethyl-sulfonyl) imide imidazolium-based ionic liquids as corrosion inhibitors for mild steel in hydrochloric acid solution. Ind. Eng. Chem. Res. 2012, 51, 13282-13299. 
29. Ahamad, I.; Prasad, R.; Quraishi, M.A. Thermodynamic, electrochemical and quantum chemical investigation of some Schiff bases as corrosion inhibitors for mild steel in hydrochloric acid solutions. Corros. Sci. 2010, 52, 933-942.

30. Gomez, B.; Likhanova, N.V.; Dominguez-Aguilar, M.A.; Martinez-Palou, R.; Vela, A.; Gazquez, J.L. Quantum chemical study of the inhibitive properties of 2-pyridyl-azoles. J. Phys. Chem. B. 2006, 110, 8928-8934.

31. Yan, Y.; Wang, X.; Zhang, Y.; Wang, P.; Zhang, J. Theoretical evaluation of inhibition performance of purine corrosion inhibitors. Mol. Sim. 2013, 39, 1034-1041.

32. Echegaray, E.; Cárdenas, C.; Rabi, S.; Rabi, N.; Lee, S.; Zadeh, F.H.; Toro-Labbe, A.; Anderson, J.S.M.; Ayers, P.W. In pursuit of negative Fukui functions: Examples where the highest occupied molecular orbital fails to dominate the chemical reactivity. J. Mol. Model. 2013, 19, 2779-2783.

33. Yang, W.; Mortier, W.J. The use of global and local molecular parameters for the analysis of the gas-phase basicity of amines. J. Am. Chem. Soc. 1986, 108, 5708-5711.

34. Becke, A.D. Density-functional exchange-energy approximation with correct asymptotic behavior. Phys. Rev. A 1988, 38, 3098-3100.

35. Lee, C.; Yang, W.; Parr, R.G. Development of the Colle-Salvetti correlation-energy formula into a functional of the electron density. Phys. Rev. B 1988, 37, 785-789.

36. Frisch, M.J.; Trucks, G.W.; Schlegel, H.B.; Scuseria, G.E.; Robb, M.A.; Cheeseman, J.R.; Scalmani, G.; Barone, V.; Mennucci, B.; Petersson, G.A.; et al. Gaussian 09, Revision D.01; Gaussian, Inc.: Wallingford, CT, USA, 2009.

(C) 2015 by the authors; licensee MDPI, Basel, Switzerland. This article is an open access article distributed under the terms and conditions of the Creative Commons Attribution license (http://creativecommons.org/licenses/by/4.0/). 